\title{
Clinical, electrophysiological, and immunopathological study of peripheral nerves in Hansen's disease
}

\author{
WAFAA RAMADAN,* BASMA MOURAD,* \\ WAEL FADEL, $* *$ \& ENAS GHORABA* \\ Departments of *Dermatology and **Neurology, Faculty of Medicine, \\ Tanta University, Tanta, Egypt
}

Accepted for publication 18 October 2000

\begin{abstract}
Summary Hansen's disease is a disease of peripheral nerves. Some patients develop peripheral neuropathy before the diagnosis of the disease, and others develop these complications after starting therapy. Electrophysiological (EP) studies were carried out in Hansen's disease patients. This work studied the neural deficits, electromyography (EMG) and motor nerve conduction (MNC) variables in different types of leprosy and the immunopathology of sural nerve tissue in patients with severe neural deficits. Forty leprosy patients had neurological examinations and EP study. Histopathological and immunopathological study of sural nerve biopsy specimens was performed for 10 patients with severe neural deficits. The results of the neurological study showed that there was involvement of cranial nerves, muscular system, motor reflexes and sensory system and trophic and vasomotor changes. EP study showed significant changes in EMG of abductor digiti minimi in patients as compared to controls. MNC variables of common peroneal nerve were abnormal in $80 \%$ of all patients, MNC of median nerve was abnormal in $72.5 \%$, while MNC of ulnar nerve was abnormal in $70 \%$ and SNC of ulnar nerve was abnormal in $77.5 \%$ of the total. In conclusion, electrophysiological investigations have an important role in the detection of muscle denervation and neuropathic changes in leprosy patients. These investigations are safe, rapid and non-invasive techniques. On the other hand immunopathological study revealed that the degree of immune positivity correlated with the degree of nerve fibrosis.
\end{abstract}

\section{Introduction}

Although its overall prevalence is decreasing, leprosy continues to be a major cause of neuropathy worldwide, ${ }^{1}$ as Mycobacterium leprae has the capacity to invade the peripheral nervous system and cause neuropathy. ${ }^{2}$ Leprous neuropathy is characterized by involvement of dermal nerves and superficial peripheral nerve trunks in cooler body regions. ${ }^{1}$ There are four possible mechanisms of nerve damage in all forms of HD: (1) the presence of M. leprae or its antigens at cooler sites; (2) trauma of superficially placed nerve trunks; (3) increased

Correspondence to: W. Ramadan 
intraneural pressure; and (4) vascular changes in intraneural blood vessels. ${ }^{3}$ HD leads to change in muscle function resulting in muscle imbalances with deformity of soft tissues and joints. ${ }^{4}$ The precise pathophysiological mechanism of peripheral neuropathy is not yet clear. It is not due to the invasion of nerves by living bacilli but it may be due to a later immune response from antigen-antibody reaction to dead bacilli and the peripheral nerves become fibrosed from mechanical stress. ${ }^{4}$

AIM OF THE WORK

This work studied the neural deficits and electrophysiological changes in different types of leprosy and the immunopathological status of the neural tissue in patients with severe neural deficits, to increase our insight into the pathophysiology of neural involvement in leprosy.

\section{Materials and methods}

Forty treated (received MDT) leprosy patients (5 PN, 2 TT, $16 \mathrm{BT}, 2 \mathrm{BL}$, and $15 \mathrm{LL}$ ) and 10 normal healthy persons (matching the same age and sex of the patients) serving as control were the subject of this study. The patients were 26 males and 14 females and their age ranged from 19 to 80 years with a mean value of $44.9 \pm 14.57$. The duration of the disease ranged from 6 months to 40 years. Eighteen of these patients had experienced leprosy reactions (7 LL, $10 \mathrm{BT}$ and $1 \mathrm{BL}$ ).

\section{METHODS}

All patients and controls had complete history taking, thorough clinical and dermatological examinations, and full neurological examinations: examination of cranial nerves, peripheral nerves, motor system (muscles and motor reflexes) and sensory system (superficial and deep sensations).

\section{Cranial nerve assessment}

This was carried out by the detection of clinical manifestations of nerve impairment, e.g. optic nerve (distributed visual acuity, and colour vision), trigeminal nerve (hypothesia of the face, wasting of pterygoid, masseter and temporalis muscles and decreased or lost corneal reflex), facial nerve (lower motor neuron facial paralysis), cochleovestibular nerve (decreased acuity of hearing), glossopharyngeal nerve (decreased pharyngeal reflex) and vagus nerve (hoarseness of voice and dysphagia).

\section{Examination of specific peripheral nerves}

The ulnar, median and common peroneal nerves were palpated at the elbow, wrist and knee respectively. ${ }^{5}$

\section{Muscle power assessment}

This was performed by testing the contraction of the muscle against gravity and resistance. 
Sensory system assessment

Superficial sensory system was assessed by using the pin prick test for pain sensation, hot test tube for temperature and a piece of thin paper, a feather or a wisp of cotton-wool for light touch sensation in both upper and lower limbs. Testing joint, vibration and pressure sensations assessed the deep sensory system.

\section{INVESTIGATIONS}

- Slit skin smear for all patients for the confirmation of diagnosis and classification of patients.

- Electrophysiological study including:

Needle EMG: The detection and recording of the electrical activity from a portion of a muscle (recording of motor unit potentials). The apparatus used was the Dantec Neuromatic 2000 C.2-channel. The muscles examined were the abductor pollicis brevis for testing the integrity of the median nerve, abductor digiti minimi for testing the ulnar nerve and extensor digitorum brevis for testing the common peroneal nerve. For each muscle EMG was done in three phases: during insertion of needle, at rest and at full volition. 6

Normal EMG: Complete electric silence at rest. With minimal voluntary contraction, individual motor unit potentials are seen, this represents the summation of membrane action potentials of many muscle fibres, which innervated by the same anterior horn cell (the motor unit). With increasing contraction, more units are recruited and the firing rate increases. Since individual motor units cannot be distinguished, this is referred to as a complete interference pattern. ${ }^{6}$

Abnormal EMG: Changes with neuropathy: these include, fibrillation, fasciculation, giant motor unit potentials and reduced interference or recruitment pattern. ${ }^{6}$

Fibrillation: the contraction of a single muscle fibre, which appears when the muscle fibre has lost its nerve supply. ${ }^{6}$

Fasciculation: the spontaneous or involuntary contraction of a motor unit or a small group of motor units. The waveforms are bizarre and irregular, occurring most of ten in motor neuron disease and may occur in normal persons after exhausted exercise or with general fatigue. ${ }^{6}$

Giant motor unit potentials: occur in chronic neuropathy, where there is incomplete denervation. The surviving axons from sprouts, which reinnervate neighbouring denervated muscle fibre, leads to enlargement of the motor units. ${ }^{6}$

Reduced interference pattern: the reduction in the number of motor units in a denervated muscle diminishes the interference pattern on voluntary muscle contraction. ${ }^{6}$

Changes with myopathy: motor unit potential is lower in amplitude and shorter in duration than normal, and there is reduced interference pattern. ${ }^{6}$

Motor nerve conduction (MNC) variables: These include motor nerve conduction velocity (MCV), distal latency (DL), amplitude (amp) and stimulus strength (st.st). The apparatus used for EMG measures them. ${ }^{6}$

MCV: recording muscle action potential from the stimulation of motor nerves. ${ }^{6}$

DL: the time from the onset of stimulus artifact to the onset of response. ${ }^{6}$

St.st.: measures the strength of muscle contraction due to electric stimulation of 
motor nerves. The stimulating electrodes are placed on the left end of the nerve, and the recording leads are on the right end.

Figure 1 illustrates the recording situation. Stimulation is started gradually. At the beginning there is no action potential, because the stimulus is subthreshold. Increasing the stimulus strength elicits the appearance of a small action potential when the nerve threshold is reached. By still further increasing the intensity of stimulation, the action potential of the nerve begins to grow in amplitude, up to a maximum. This is the maximal response, evoked by the maximal stimulation. Points between threshold and maximal stimulation are called either suprathreshold or submaximal. Stimulating with weak currents, activates the most excitable fibres in the nerve, with increasing the stimulus strength, fibres of lower excitability or higher threshold begin to recruit. ${ }^{7}$

Sensory nerve conduction (SNC) variables of ulnar nerve only: These include sensory conduction velocity (SCV), DL, amp., and st.st. This was done in a similar manner to MNC. ${ }^{6}$

$S C V$ : recording nerve action potential from the stimulation of sensory nerves. ${ }^{6}$

- Histopathological study:

Nerve biopsy specimens of sural nerve were taken from 10 patients with severe neurological deficits (diagnosed clinically by detecting the impairment of motor, sensory and/or autonomic nerve function and by EP to detect the extent of nerve impairment). The age of these patients ranged from 50 to 80 years and the duration of the disease ranged from 15 to 40 years. The nerve biopsy specimen was taken from the most affected limb. Each specimen was divided into two halves, one half for histopathological study [stained with H\&E stain and Mallory's phosphotungistic acid haematoxylin (PTAH) stain], ${ }^{8}$ and the other half for immunopathological study.

- Immunopathological study:

Streptavidin-biotin immunoperoxidase (ABIP) staining and Immustain Polyclonal Rabbit Primary Antibody set for IgG and IgM (DPC Diagnostic Products Corporation). ${ }^{9}$

1.

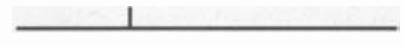

SUBTHRESHOLD

2 .

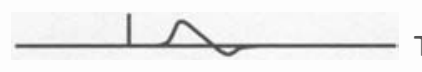

THRESHOLD

3.

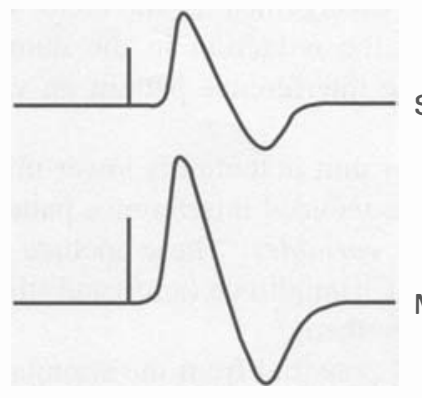

SUBMAXIMAL

MAXIMAL

Figure 1. Effects of different stimulus strength on the amplitude of the action potential during stimulation of a whole nerve. 


\section{Method $^{9}$}

1. Prepare buffered wash working solution.

2. Prepare duplicate slides for each specimen.

3. Removal of paraffin and rehydration of sections.

4. Place blocking endogenous peroxidase on each slide.

5. Trypsinization of tissue sections in 0.1 trypsin solution.

6. Exposure to primary antibody B1 Immustain Polyclonal Rabbit Primary Antibody set for IgG and DPC's Immustain Polyclonal Rabbit antibody set for IgM.

7. Exposure to polyclonal linking reagent.

8. Exposure for streptavidin enzyme.

9. Colour development: put several drops of DI-amino-benzidine working colour reagent on each slide, then counter stain with Mayer's haematoxylin.

10. Interpretation of the results: view the slides on bright-field microscope. The intensity of staining was graded as follows: + (mild), ++ (moderate) and +++ (marked).

\section{Results}

\section{CLINICAL RESULTS}

Table I shows the distribution of leprosy patients according to age, duration of the disease and type of leprosy.

\section{NEUROLOGICAL RESULTS}

Table 2 shows leprosy patients with impairment of:

- Cranial nerves: the trigeminal nerve was the most common cranial nerve impaired, being involved in 19 patients $(47 \cdot 5 \%)$. The predominant manifestations of trigeminal nerve

Table 1. Distribution of leprosy patients studied according to age, duration of the disease, and type of leprosy

\begin{tabular}{|c|c|c|c|c|c|c|}
\hline & \multicolumn{5}{|c|}{ Types of leprosy patients $(n=40)$} & \multirow[b]{2}{*}{ Total $(n=40)$} \\
\hline & LL $(n=15)$ & $\mathrm{BL}(n=2)$ & $\mathrm{BT}(n=16)$ & $\mathrm{TT}(n=2)$ & $\mathrm{PN}(n=5)$ & \\
\hline \multicolumn{7}{|l|}{ Age/years } \\
\hline$<20$ & - & 1 & - & - & 1 & 2 \\
\hline $20-40$ & 3 & 1 & 4 & 2 & 4 & 14 \\
\hline $41-60$ & 10 & - & 9 & - & - & 19 \\
\hline $71-80$ & 4 & - & 1 & - & - & 5 \\
\hline \multicolumn{7}{|c|}{ Duration/years } \\
\hline$<1$ & $=$ & 1 & - & - & 2 & 3 \\
\hline $1-5$ & 4 & - & 2 & 1 & 3 & 10 \\
\hline $6-10$ & 2 & 1 & 5 & 1 & - & 9 \\
\hline $11-15$ & 1 & - & 4 & - & - & 5 \\
\hline $16-20$ & 3 & - & 1 & - & - & 4 \\
\hline$>20$ & 5 & - & 4 & - & - & 9 \\
\hline
\end{tabular}


affection were mainly sensory manifestations in the form of hypothesia of the face in 12 patients, anaesthesia of the face in seven patients and loss of corneal reflex in all of them. Motor manifestations were detected in 10 patients only (wasting and weakness of temporalis and masseter muscles in seven patients, and deviation of the lower jaw due to the affection of pterygoid muscle in three patients).

- Muscular system: the commonest disabilities in muscles were manifested by: claw hand(s) in 13 patients (32.5\%), wasting of hand(s) and/or forearm(s) in 31 patients (77.5\%) [unilateral distal 1/3 wasting towards ulnar side (flexors of wrist, long flexors of 4th and 5th digits and intrinsic hand muscles) in 10 cases, distal 1/3 wasting towards radial side (triceps, brachioradialis, wrist, finger and thumb extensors) in three cases, unilateral wasting of hypothenar muscles in four cases, bilateral distal $2 / 3$ wasting in five cases and bilateral distal $1 / 3$ wasting in nine cases] and lower limb(s) wasting in 21 patients $(52.5 \%)$ [wasting of distal leg muscles towards peroneal side in four cases, wasting of foot muscles in three cases, bilateral wasting of distal $1 / 3$ of legs in three cases and bilateral distal $2 / 3$ wasting of legs in 11 cases], hypotonia of upper and lower limbs in 18 patients (45\%) and 13 patients $(32.5 \%)$, respectively, and decreased muscle power of upper and lower limbs in 12 patients $(30 \%)$ and 11 patients $(27.5 \%)$, respectively.

- Motor reflexes: supinator reflex was the most affected, diminished in 18 patients (45\%); least affected were triceps and knee reflexes, each diminished in seven patients (17.5\%).

- Sensory system: superficial and deep sensations were affected as shown.

- Trophic and vasomotor changes: the most common manifestations were resorption of fingers in 18 patients (45\%), anhidrosis in 17 patients $(42.5 \%)$ and resorption of toes in 13 patients $(32 \cdot 5 \%)$.

With regard to nerve thickness, thickened ulnar nerve was found in 17 patients, thickened median nerve in five patients, thickened radial nerve in two patients, thickened great auricular nerve in nine patients and thickened common peroneal nerve in 10 patients.

\section{ELECTROPHYSIOLOGICAL RESULTS}

\section{EMG results}

Table 3 shows EMG results of some muscles in leprosy patients. There was abnormal EMG of abductor pollicis brevis in 29 patients (two had fibrillation potentials, 27 had reduced or discrete recruitment pattern), abnormal EMG of abductor digiti minimi in 28 patients (four had fibrillation potentials, 24 had reduced or discrete recruitment pattern) and abnormal EMG of extensor digitorum brevis in 24 patients (two had fibrillation potentials, 22 had reduced or discrete recruitment pattern).

Table 4 shows statistical analysis of EMG amplitude of some muscles in leprosy patients and controls. There was a non-significant reduction in EMG amp. of abductor pollicis brevis in patients as compared to controls, significant reduction in EMG amp. of abductor digiti minimi and non-significant reduction in EMG amp. of extensor digitorum brevis.

\section{Nerve conduction results}

Tables 5, 6 and 7 show statistical analysis of MNC variables of median nerve, ulnar nerve (Figure 2) and common peroneal nerve, respectively. There was a statistically significant 
Table 2. Neurological manifestations in different types of leprosy patients studied

Types of leprosy patients $(n=40)$

\begin{tabular}{|c|c|c|c|c|c|c|}
\hline Neurological manifestations & LL & $\mathrm{BL}$ & BT & TT & PN & Total \\
\hline \multicolumn{7}{|l|}{ Cranial nerves affected: } \\
\hline Optical nerve & 7 & 1 & - & - & - & 8 \\
\hline Trigeminal nerve & 17 & 1 & - & 1 & - & 19 \\
\hline Facial nerve & - & - & 5 & 2 & - & 7 \\
\hline Glossopharyngeal & 3 & - & 3 & - & - & 6 \\
\hline Vagus & 7 & - & 6 & - & - & 13 \\
\hline Cochleovestibular & 3 & 1 & 1 & - & - & 5 \\
\hline \multirow{2}{*}{\multicolumn{7}{|c|}{$\begin{array}{l}\text { Muscular system: } \\
\text { Disability: }\end{array}$}} \\
\hline & & & & & & \\
\hline Claw hand & 3 & - & 7 & 1 & 2 & 13 \\
\hline Hand drop & 1 & - & - & - & - & 1 \\
\hline Flexion deformity (toes) & 2 & - & - & - & 1 & 3 \\
\hline \multicolumn{7}{|l|}{ Muscle wasting of: } \\
\hline Upper $\operatorname{limb}(\mathrm{s})$ & 12 & 1 & 13 & 2 & 3 & 31 \\
\hline Lower limb(s) & 12 & - & 5 & 1 & 3 & 21 \\
\hline \multicolumn{7}{|l|}{ Hypotonia of: } \\
\hline Upper limb(s) & 6 & 11 & 1 & - & - & 18 \\
\hline Lower limb(s) & 7 & - & 4 & - & 2 & 13 \\
\hline \multicolumn{7}{|l|}{ Decreased muscle power of: } \\
\hline Upper limb(s) & 5 & 7 & - & - & - & 12 \\
\hline Lower $\operatorname{limb}(\mathrm{s})$ & 7 & 4 & - & - & - & 11 \\
\hline \multicolumn{7}{|l|}{ Motor reflexes: } \\
\hline \multicolumn{7}{|l|}{ Diminished } \\
\hline Biceps reflex & 5 & - & 3 & - & - & 8 \\
\hline Supinator reflex & 7 & - & 10 & 1 & - & 18 \\
\hline Triceps reflex & 4 & - & 3 & - & - & 7 \\
\hline Knee reflex & 5 & - & 2 & - & - & 7 \\
\hline Ankle reflex & 6 & - & 2 & - & 2 & 10 \\
\hline \multicolumn{7}{|l|}{ Loss of: } \\
\hline Ankle reflex & 4 & - & 2 & - & - & 6 \\
\hline \multicolumn{7}{|l|}{ Sensory system: } \\
\hline \multirow{2}{*}{\multicolumn{7}{|c|}{$\begin{array}{l}\text { Superficial sensation: } \\
\text { Mononeuropathy on: }\end{array}$}} \\
\hline & & & & & & \\
\hline Ulnar side & 3 & 1 & 7 & 1 & 1 & 13 \\
\hline Radial side & 1 & - & - & 1 & - & 2 \\
\hline Peroneal side & 4 & - & 1 & - & 1 & 6 \\
\hline Glove and stocking hypothesia & 8 & - & 6 & - & 1 & 15 \\
\hline Glove hypothesia & - & 1 & 1 & - & 1 & 3 \\
\hline Stocking hypothesia & 2 & - & 1 & - & - & 3 \\
\hline Maculoanaesthetic patches & & & & & & \\
\hline \multicolumn{7}{|l|}{ Deep sensation: } \\
\hline Diminished joint \& vibration sensation & 8 & - & 5 & - & - & 13 \\
\hline \multicolumn{7}{|l|}{ Trophic \& vasomotor changes: } \\
\hline Resorption of fingers & 8 & - & 10 & - & - & 18 \\
\hline Resorption of toes & 9 & - & 4 & - & - & 13 \\
\hline Fissuring foot & 3 & - & 6 & 1 & 3 & 13 \\
\hline Plantar ulceration & 3 & - & - & - & - & 3 \\
\hline Joint deformity & 4 & - & 2 & - & - & 6 \\
\hline Osteoarthritis & 2 & - & 3 & - & - & 5 \\
\hline Anhidrosis & 5 & - & 8 & 1 & 3 & 17 \\
\hline
\end{tabular}


Table 3. EMG results of some muscles in leprosy patients

\begin{tabular}{lccc}
\hline & & \multicolumn{2}{c}{ Patients $(n=40)$} \\
\cline { 2 - 4 } & & \multicolumn{2}{c}{ Abnormal } \\
\cline { 3 - 4 } EMG of & Normal & Fibrillation potentials & Reduced or discrete recruitment pattern \\
\hline Abductor pollicis brevis & 11 & 2 & 27 \\
Abductor digiti minimi & 12 & 4 & 24 \\
Extensor digitorum brevis & 16 & 2 & 22 \\
\hline
\end{tabular}

Table 4. Statistical analysis of EMG amplitude of some muscles in leprosy patients and controls. mv = millivolt

\begin{tabular}{|c|c|c|c|c|c|c|}
\hline & \multicolumn{6}{|c|}{ EMG amplitude of } \\
\hline & \multicolumn{2}{|c|}{ Abductor pollicis brevis } & \multicolumn{2}{|c|}{ Abductor digiti minimi } & \multicolumn{2}{|c|}{ Extensor digitorum brevis } \\
\hline & $\begin{array}{l}\text { Patients } \\
n=40\end{array}$ & $\begin{array}{l}\text { Control } \\
n=10\end{array}$ & $\begin{array}{c}\text { Patients } \\
n=40\end{array}$ & $\begin{array}{l}\text { Control } \\
n=10\end{array}$ & $\begin{array}{c}\text { Patients } \\
n=40\end{array}$ & $\begin{array}{l}\text { Control } \\
n=10\end{array}$ \\
\hline Range & $0 \cdot 3-2 \cdot 1 \mathrm{mv}$ & $0 \cdot 5-2 \cdot 1 \mathrm{mv}$ & $0.2-1.8 \mathrm{mv}$ & $0.8-2.3 \mathrm{mv}$ & $0 \cdot 32-2 \cdot 0 \mathrm{mv}$ & $0.5-0.2 \mathrm{mv}$ \\
\hline Mean & $1 \cdot 11$ & $1 \cdot 25$ & 0.91 & 1.59 & 1.09 & $1 \cdot 25$ \\
\hline$\pm \mathrm{SD}$ & $0 \cdot 58$ & 0.53 & $0 \cdot 67$ & $0 \cdot 49$ & 0.54 & 0.57 \\
\hline $\mathrm{T}$ & $0 \cdot 71$ & & $3 \cdot 63$ & & $0 \cdot 86$ & \\
\hline $\mathrm{P}$ & 0.05 & & $0.01 *$ & & 0.05 & \\
\hline
\end{tabular}

* Significant.

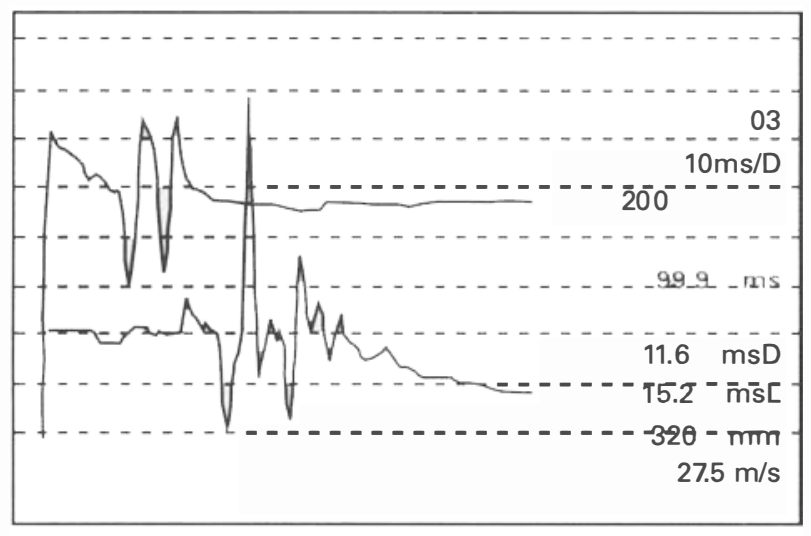

Figure 2. Motor nerve conduction study of ulnar nerve in a patient with LL showing decreased NCV and Amp. with increased DL and St. st.

reduction in $\mathrm{MCV}$, significant prolongation of $\mathrm{DL}$, and significant reduction of amp. of median nerve in $72.5 \%$ of patients, of ulnar nerve in $70 \%$ and of common peroneal nerve in $80 \%$ of patients. There was a significant increase of St. st of all previous nerves in $100 \%$ of patients.

Table 8 shows statistical analysis of SNC variables of ulnar nerve. There was a significant 
Table 5. Statistical analysis of motor nerve conduction variables of median nerve in leprosy patients and controls. $\mathrm{ms}=$ millisecond, $\mathrm{m} / \mathrm{s}=$ meter/second, $\mu \mathrm{v}=$ microvolt

\begin{tabular}{|c|c|c|c|c|c|c|c|c|}
\hline \multirow[b]{2}{*}{ Median motor nerve variables } & \multicolumn{3}{|c|}{ Patients $(n=40)$} & \multicolumn{3}{|c|}{ Controls $(n=10)$} & \multirow[b]{2}{*}{$t$} & \multirow[b]{2}{*}{$P$} \\
\hline & Range & Mean & $\pm \mathrm{SD}$ & Range & Mean & $\pm \mathrm{SD}$ & & \\
\hline $\mathrm{CV} \mathrm{m} / \mathrm{s}$ & $0-51 \cdot 6$ & $31 \cdot 11$ & $17 \cdot 33$ & $48 \cdot 2-58 \cdot 2$ & $52 \cdot 01$ & $3 \cdot 03$ & $7 \cdot 20$ & $<0.001^{*}$ \\
\hline D.L. ms & $0-15.6$ & $7 \cdot 23$ & $4 \cdot 75$ & $3 \cdot 04-4 \cdot 22$ & $3 \cdot 91$ & $0 \cdot 38$ & $4 \cdot 37$ & $<0.001^{*}$ \\
\hline Amp mv & $0-10$ & 6.94 & $3 \cdot 22$ & $11 \cdot 5-15$ & $13 \cdot 05$ & 1.04 & $10 \cdot 09$ & $<0.001^{*}$ \\
\hline St. st. $\mu \mathrm{v}$ & $37-99 \cdot 9$ & $90 \cdot 82$ & $21 \cdot 26$ & $8 \cdot 13$ & $10 \cdot 50$ & 1.96 & $23 \cdot 50$ & $<0.001^{*}$ \\
\hline
\end{tabular}

*Significant.

Table 6. Statistical analysis of motor nerve conduction variables of ulnar nerve in leprosy patients and controls

\begin{tabular}{|c|c|c|c|c|c|c|c|c|}
\hline \multirow[b]{2}{*}{ Ulnar motor nerve variable } & \multicolumn{3}{|c|}{$\begin{array}{c}\text { Patients } \\
n=40\end{array}$} & \multicolumn{3}{|c|}{$\begin{array}{c}\text { Controls } \\
n=10\end{array}$} & \multirow[b]{2}{*}{$r$} & \multirow[b]{2}{*}{$P$} \\
\hline & Range & Mean & $\pm \mathrm{SD}$ & Range & Mean & $\pm \mathrm{SD}$ & & \\
\hline $\mathrm{CV} \mathrm{m} / \mathrm{s}$ & $0-50$ & $26 \cdot 14$ & $17 \cdot 65$ & $51 \cdot 6-66 \cdot 9$ & $58 \cdot 13$ & $4 \cdot 88$ & $10 \cdot 03$ & $<0.001^{*}$ \\
\hline D.L. ms & $0-18$ & $8 \cdot 29$ & $5 \cdot 97$ & $2 \cdot 36-3 \cdot 12$ & $2 \cdot 79$ & $0 \cdot 23$ & $5 \cdot 82$ & $<0.001^{*}$ \\
\hline Amp mv & $0-44$ & $3 \cdot 30$ & $7 \cdot 01$ & $11 \cdot 3-15$ & $13 \cdot 02$ & $1 \cdot 27$ & $4 \cdot 34$ & $<0.001^{*}$ \\
\hline St. St. $\mu \mathrm{v}$ & $80-99 \cdot 9$ & $97 \cdot 91$ & $6 \cdot 05$ & $8 \cdot 13$ & $11 \cdot 10$ & $1 \cdot 91$ & $44 \cdot 54$ & $<0.001 *$ \\
\hline
\end{tabular}

* Significant.

Table 7. Statistical analysis of motor nerve conduction variables of common peroneal nerve in leprosy patients and controls

\begin{tabular}{|c|c|c|c|c|c|c|c|c|}
\hline \multirow{2}{*}{$\begin{array}{l}\text { Common peroneal } \\
\text { motor nerve variable }\end{array}$} & \multicolumn{3}{|c|}{$\begin{array}{l}\text { Patients } \\
n=40\end{array}$} & \multicolumn{3}{|c|}{$\begin{array}{c}\text { Controls } \\
n=10\end{array}$} & \multirow[b]{2}{*}{$t$} & \multirow[b]{2}{*}{$P$} \\
\hline & Range & Mean & $\pm \mathrm{SD}$ & Range & Mean & $\pm \mathrm{SD}$ & & \\
\hline $\mathrm{CV} \mathrm{m} / \mathrm{s}$ & $0-41.3$ & $28 \cdot 27$ & 13.98 & $45 \cdot 4-51 \cdot 8$ & $47 \cdot 84$ & $2 \cdot 29$ & 8.42 & $<0.001^{*}$ \\
\hline D.L. ms & $0-15.2$ & $7 \cdot 77$ & $4 \cdot 85$ & $3 \cdot 76-5 \cdot 44$ & $4 \cdot 63$ & 0.63 & 3.96 & $<0.001^{*}$ \\
\hline Amp mv & $0-4$ & $2 \cdot 29$ & $1 \cdot 35$ & $9 \cdot 5-15$ & $12 \cdot 48$ & 1.99 & $15 \cdot 32$ & $<0.001 *$ \\
\hline St. St. $\mu \mathrm{v}$ & $76-99 \cdot 9$ & $96 \cdot 23$ & $8 \cdot 10$ & $9-13$ & $11 \cdot 00$ & 1.76 & 61.04 & $<0.001 *$ \\
\hline
\end{tabular}

* Significant.

Table 8. Statistical analysis of sensory nerve conduction variables of ulnar nerve in leprosy patients and controls

\begin{tabular}{|c|c|c|c|c|c|c|c|c|}
\hline \multirow[b]{2}{*}{ Ulnar sensory nerve variable } & \multicolumn{3}{|c|}{$\begin{array}{c}\text { Patients } \\
n=40\end{array}$} & \multicolumn{3}{|c|}{$\begin{array}{c}\text { Controls } \\
n=10\end{array}$} & \multirow[b]{2}{*}{$t$} & \multirow[b]{2}{*}{$P$} \\
\hline & Range & Mean & $\pm \mathrm{SD}$ & Range & Mean & $\pm \mathrm{SD}$ & & \\
\hline $\mathrm{CV} \mathrm{m} / \mathrm{s}$ & $0-36 \cdot 6$ & $16 \cdot 61$ & $14 \cdot 25$ & $47 \cdot 3-54 \cdot 2$ & $49 \cdot 92$ & $2 \cdot 65$ & $13 \cdot 86$ & $<0.001^{*}$ \\
\hline D.L. ms & $0-15$ & $7 \cdot 87$ & $5 \cdot 56$ & $2 \cdot 2-3 \cdot 08$ & $2 \cdot 68$ & $0 \cdot 30$ & $5 \cdot 87$ & $<0.001 *$ \\
\hline Amp mv & $0-60$ & $24 \cdot 13$ & $21 \cdot 00$ & $17-100$ & $42 \cdot 13$ & $30 \cdot 77$ & $2 \cdot 20$ & $<0.001^{*}$ \\
\hline St. St. $\mu \mathrm{v}$ & $40-93 \cdot 5$ & $47 \cdot 25$ & $8 \cdot 38$ & $8 \cdot 8-12 \cdot 4$ & $10 \cdot 08$ & $1 \cdot 27$ & $13 \cdot 88$ & $<0 \cdot 001^{*}$ \\
\hline
\end{tabular}

\footnotetext{
* Significant.
} 
Table 9. Evaluation of MNC variables of different nerves and SNC variables of ulnar nerve

\begin{tabular}{|c|c|c|c|c|c|c|c|c|}
\hline \multirow[b]{4}{*}{ Nerve } & \multicolumn{7}{|c|}{ Nerve conduction variables } & \\
\hline & \multicolumn{2}{|c|}{ Normal } & \multirow{2}{*}{\multicolumn{2}{|c|}{$\begin{array}{c}\text { Conducting } \\
\text { Nerve }\end{array}$}} & \multicolumn{2}{|c|}{ Abnormal } & \multirow{2}{*}{\multicolumn{2}{|c|}{ Total }} \\
\hline & & & & & \multicolumn{2}{|c|}{$\begin{array}{c}\text { Non-conducting } \\
\text { nerve }\end{array}$} & & \\
\hline & $n$ & $\%$ & $n$ & $\%$ & $n$ & $\%$ & $n$ & $\%$ \\
\hline Median & 11 & $27 \cdot 5$ & 23 & $57 \cdot 5$ & 6 & $15 \cdot 0$ & 29 & $72 \cdot 5$ \\
\hline Ulnar (motor) & 12 & $30 \cdot 0$ & 20 & $50 \cdot 0$ & 8 & $20 \cdot 0$ & 28 & $70 \cdot 0$ \\
\hline Common peroneal & 8 & $22 \cdot 0$ & 28 & $60 \cdot 0$ & 4 & $10 \cdot 0$ & 32 & $80 \cdot 0$ \\
\hline Ulnar (sensory) & 9 & $22 \cdot 5$ & 19 & $47 \cdot 5$ & 12 & $30 \cdot 0$ & 31 & $77 \cdot 5$ \\
\hline
\end{tabular}

reduction of SCV, significant prolongation of DL, significant reduction of amp. in $77.5 \%$ of patients and significant increase of st. st. in $100 \%$ of patients.

Table 9 shows that MNC of median nerve was abnormal in 29 patients $(72.5 \%)$ (the nerve was non-conducting in six patients). MNC of ulnar nerve was abnormal in 28 patients $(70 \%)$ of the total (non-conducting nerve in eight patients) and MNC of common peroneal was abnormal in 32 patients $(80 \%)$ of the total (non-conducting nerve in four patients). SNC of ulnar nerve was abnormal in 31 patients (77.5\%) (non-conducting nerve in 12 patients), while st. st. was abnormal in all patients.

\section{HISTOPATHOLOGICAL RESULTS}

Table 10 shows the distribution of the patients who were included in the histopathological study according to age, duration of the disease and type of leprosy.

Table 11 shows the histopathological changes of sural nerve biopsy specimens in leprosy patients by using different stains.

Table 10. Distribution of leprosy patients who were used for histopathological study according to age, duration of disease and type of disease

\begin{tabular}{llll}
\hline & \multicolumn{2}{l}{ Patients $(n=10)$} & \\
\cline { 2 - 3 } & LL & BT & Total $(n=10)$ \\
\hline Age (years) & & & \\
$50-60$ & 4 & 2 & 6 \\
$61-70$ & 1 & 2 & 3 \\
$>70$ & 1 & - & 1 \\
Duration (years) & & & \\
$20-25$ & 3 & 2 & 5 \\
$26-30$ & 2 & 2 & 4 \\
$>30$ & 1 & - & 1 \\
\hline
\end{tabular}




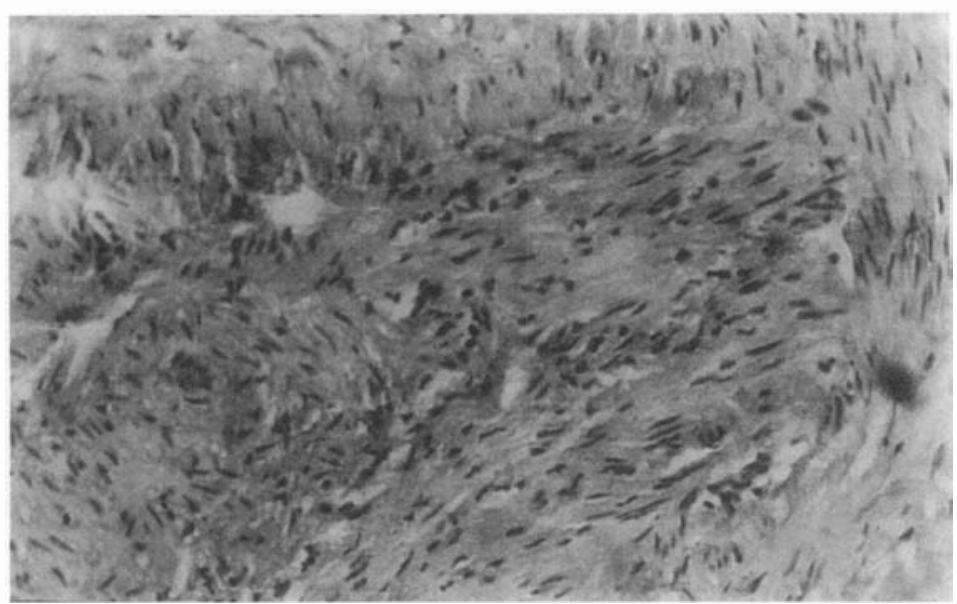

Figure 3. Marked nerve fibrosis replacing the endoneural tissue in $\mathrm{BT}(\mathrm{H} \& \mathrm{E} \times 125)$.

\section{H\&E STAIN}

There was fibrosis of the intraneural tissue, [marked fibrosis of endoneural tissue in two patients (20\%) out of 10 (Figure 3), moderate in six patients $(60 \%)$ and mild in two patients (20\%)], destruction of the perineurium, areas of breakdown of myelin sheath, degenerative changes of Schwann cells and no evidence of invading inflammatory cell infiltrate in sural nerve biopsy specimens in most patients (Table 11).

Table 11. Histopathological changes of sural nerve biopsy specimens in leprosy patients by using different stains

\begin{tabular}{|c|c|c|}
\hline \multirow[b]{2}{*}{ Histopathological changes } & \multicolumn{2}{|c|}{ Leprosy patients $(n=10)$} \\
\hline & $\operatorname{LL}(n=6)$ & $\mathrm{BT}(n=4)$ \\
\hline \multicolumn{3}{|l|}{$H \& E:$} \\
\hline Mild fibrosis & - & 2 \\
\hline Moderate fibrosis & 4 & 2 \\
\hline Severe fibrosis & 2 & - \\
\hline \multicolumn{3}{|l|}{ Mallory's PTAH: } \\
\hline Fibrosis & 6 & - \\
\hline No fibrosis & - & 4 \\
\hline \multicolumn{3}{|l|}{$\begin{array}{l}\text { ABIP: } \\
\text { IgG deposition }\end{array}$} \\
\hline+ & _ & 2 \\
\hline++ & 4 & 2 \\
\hline+++ & 2 & - \\
\hline \multicolumn{3}{|l|}{ IgM deposition } \\
\hline+ & - & 2 \\
\hline++ & 1 & 2 \\
\hline+++ & 5 & - \\
\hline
\end{tabular}




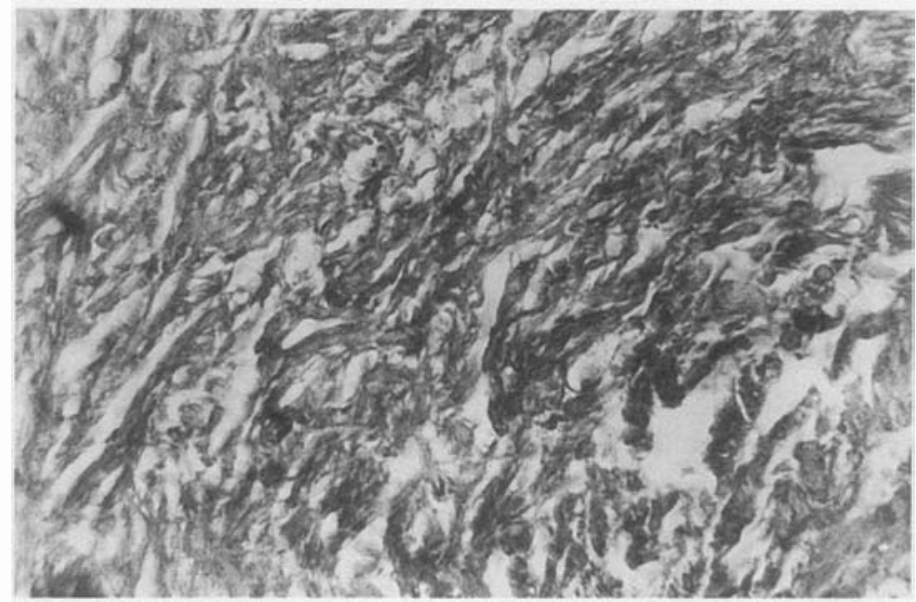

Figure 4. Extensive nerve fibrosis with scattered scanty myelinated nerve fibres in BT (Mallory's $\times 125$ ).

HISTOCHEMICAL STAIN (MALLORY'S PTAH)

There was predominant fibrosis of the nerve trunk in six cases $(60 \%)$ out of 10 (Figure 4 and Table 11).

IMMUNOPATHOLOGICAL RESULTS (ABIP STAIN)

There was mild deposition $(+)$ of $\mathrm{IgG}$ in two patients $(20 \%)$, moderate $(++)$ in six patients $(60 \%)$ (Figure 5), and marked $(+++)$ in two patients $(20 \%)$.

IgM deposition was mild in three patients $(30 \%)$, moderate in two patients $(20 \%)$, and marked in five patients $(50 \%)$.



Figure 5. Moderate deposits of IgG $(++)$ in sural nerve section in PN $(\mathrm{ABIP} \times 250)$. 
There were areas of uneven distribution of $\operatorname{IgG}$ and $\operatorname{IgM}$ in the neural tissue in most specimens. The antigens (IgG and $\operatorname{IgM}$ ) deposited and appeared as homogenous and reddish patches in the endoneural areas (Table 11).

\section{Discussion}

The mechanism of nerve damage in HD remains diverse and unclarified. ${ }^{10}$ It may be intrafascicular, intraneural, extrafascicular or extraneural lesions. ${ }^{11}$ Peripheral nerve involvement is usually more and appears earlier in TT than in LL and also certain nerves are affected more than others in HD. ${ }^{12}$ Croft et al. ${ }^{13}$ found that the most commonly affected nerve by function impairment was the posterior tibial (sensory) followed by the ulnar nerve.

In this study, the cranial nerves were affected in this order of sequence, the trigeminal followed by optic, then facial, vagus, glossopharyngeal, cochleovestibular and finally spinal accessory nerves. Cranial nerve impairments were more in LL except the facial nerve, which was affected only in BT. This finding was similar to that mentioned by Lubbers et al. ${ }^{14}$

Claw hand was the most common disability among patients in the present study; this indicates that ulnar nerve is the most affected nerve in leprosy patients. The impairments were noticed more in LL, and this can be attributed to long duration of the disease, the presence of large number of skin lesions, occurrence of more invasive type and frequent episodes of reaction in those patients. This agrees with the findings of other studies. ${ }^{15,16}$

In the present study, all sensory modalities (superficial and deep) were affected except deep pressure sensation, which was diminished in the advanced cases only. This agrees with the results of Andersen. ${ }^{5}$ Trophic and vasomotor changes were manifested in the form of resorption of fingers and/or toes, anhidrosis, fissuring of foot, joint deformity, osteoarthritis and plantar ulceration.

Mshana et al. ${ }^{12}$ mentioned that some nerves that appeared to be clinically normal have been shown to have pathological changes.

Van Brakel and Khawas ${ }^{17}$ recommended that all leprosy patients should have a nerve function assessment at every visit to the clinic at least during their first year of treatment and regular nerve function assessment was essential to detect silent neuropathy at an early stage and to prevent permanent impairment of nerve function. ${ }^{17}$

In the present study EMG results showed a neuropathic pattern, which could be attributed to the sequelae of nerve degeneration rather than muscle degeneration. Thus it can be suggested that the wasting of muscles encountered among leprosy patients with neuropathy may be due to neurogenic atrophy.

Werneck et al. ${ }^{18}$ stated that the involvement of skeletal striated muscles in leprosy was considered secondary due to peripheral neuropathy, and others attributed it to a primary muscle lesion. In the present study, MNC variables showed that ulnar nerve was more affected than median and common peroneal nerves; this was in agreement with the results of Antia et al. ${ }^{19}$

In this study, there was a markedly significant increase of st.st. in all patients even in cases with normal conduction velocity. This means that st. st is a very important and sensitive test for early detection of nerve involvement, which becomes abnormal before any noticeable changes in other motor nerve conduction variables.

Samant et al. ${ }^{20}$ reported that nerve conduction measurements proved to be more sensitive 
in detecting nerve function impairment, but the combination of physical palpation for nerve thickening and graded nylon test was closely comparable to measurement of nerve conduction.

In the present study, SCV of ulnar nerve was slower than $\mathrm{MCV}$, indicating that the sensory system was more affected than the motor system in leprosy patients. This agrees with the findings of other studies. ${ }^{20,21}$

Regarding the histopathological results, there was fibrosis of the intraneural tissues, destruction of the perineurium, areas of breakdown of myelin sheath, degenerative changes of Schwann cells and no evidence of invading inflammatory cell infiltrate in sural nerve biopsy specimens in most patients. Van Brakel and Khawas ${ }^{22}$ found nearly similar results.

On the other hand, Mafoyane et al. ${ }^{23}$ found chronic granulomatous infiltrate within the nerve bundles and extensive destruction and fibrosis of the nerves in patients with primary neuritic leprosy. This variation may be due to the fact that all the studied patients were chosen from those with advanced neural deficits, so fibrosis was the end result of inflammatory changes.

As regards the immunopathological results, in our study, there was marked deposition of IgG and/or IgM in specimens with extensive neural fibrosis. IgG and IgM deposition in the neural tissues may be attributed to the transmission of these deposits through the endoneural blood vessels.

Barros et al. ${ }^{24}$ found high antigenic load, demonstrated by using anti-BCG antibody (peroxidase-antiperoxidase technique) in the nerve specimens of their patients (in treated LL patients and in untreated TT patients).

In this study, the neural tissues showed areas of unequal distribution of IgG and IgM, this may be attributed to uneven involvement of nerve fascicles or may be related to the chronological occurrence of nerve damage among different nerve fibres or fascicles in the same nerve, this point needs further studies on different nerve biopsy specimens and different grades of nerve damage in a sufficient number of leprosy patients.

\section{References}

${ }^{1}$ Nations SP, Katz JS, Lyde CB, Barohn RJ. Leprous neuropathy: an American perspective. Semin Neurol, 1998; 18: $113-124$.

2 Rambukana L. How does Mycobacterium leprae target the peripheral nervous system? Trends Microbiol, 2000; 8: 23-28.

3 Job CK, Nerve damage in Hansen's disease. Part II. The Star, 1991; 50: 5-7.

4 Krotoski JB. Peripheral neuropathy and examination of the hands. The Star, 1991; 50: 1-5.

5 Andersen JG. Sensory testing under field conditions. The Star, 1990; 50: 6-7.

${ }^{6}$ Gabr M. Clinical, biochemical, and electrical study of skeletal muscles in patients with diabetic neuropathy. MD Thesis, Faculty of Medicine, Tanta University, Tanta, Egypt, 1989.

7 Eyzaguirre C, Fidone JS. Physiology of the nervous system. An introductory text. Part 1: general neurophysiology. The nerve. YearBook Medical Publishers Incorporated Chicago, 1975; pp. 20-30.

8 Bancroft JD, Stevens A. Histopathological stains and their diagnostic uses. Churchill Livingstone, Edinburgh, New York, 1974, pp 3-17.

9 Taylor CR, Kledisek G. Immunohistologic techniques in surgical pathology - a spectrum of new special stain. Hum Pathol, 12: 590-595.

10 Antia NH, Shetty VP. Nerve damage in leprosy. Int J Lepr, 1988; 56: 619-621.

11 Charosky CB, Gatti JC, Cardama JE. Neuropathies in Hansen's disease. Int J Lepr, 1983; 51: 576-586.

12 Mshana RN, Humber DP, Harboe M, Belehu A. Demonstration of mycobacterial antigens in nerve biopsies from leprosy patients using peroxidase-antiperoxidase immunoenzyme technique. Clin Immunol Immunopathol, 1983; 29: $359-368$.

13 Croft RP, Richardus JH, Nicholls PG, Smith WC. Nerve function impairment in leprosy: design, methodology, 
and intake status of a prospective cohort study of 2664 new leprosy cases in Bangladesh (The Bangladesh Acute Nerve Damage Study). Lepr Rev, 1999; 70: 140-159.

${ }^{14}$ Lubbers WJ, Schopper A, Hogeweg M, Soldenhoff R. Paralysis of facial muscles in leprosy patients with lagophthalmos. Int J Lepr, 1994; 66: 220-224.

15 Smith WCS. The epidemiology of disability in leprosy including risk factors. Lepr Rev, 1992; 63: 23-30.

16 Chopra NK, Arawal JS. Hansen's disease deformities: an epidemiological study in a multidrug therapy project. Star, 1990; 49: 9-12.

17 Van Brakel WH, Khawas IB. Silent neuropathy in leprosy: an epidemiological description. Lepr Rev, 1994; 65: 350-360.

18 Werneck LC, Teive HA, Scola RH. Muscle involvement in leprosy. Study of the anterior tibial muscle in 40 patients. Arq Neuropsiquiatr Sep. 1999; 57: 723-734.

19 Antia NH, Pandya SS, Dastur DK. Nerves in the arm in leprosy. Clinical, electrodiagnostic and operative aspects. Int J Lepr, 1970; 38: 12-28.

20 Samant G, Shetty VP, Uplekar MW, Antia NH. Clinical and electrophysiological evaluation of nerve function impairment following cessation of multidrug therapy in leprosy. Lepr Rev, 1999; 70: 10-20.

21 Vegrhese M, Ittimani KV, Satyanarayan KR. A study of the conduction velocity of the motor fibres of ulnar and median nerves in leprosy. Int J Lepr, 1970; 38: 271-277.

22 Van Brakel WH, Khawas IB. Nerve damage in leprosy: An epidemiological and clinical study of 396 patients in west Nepal. Part 1. Definitions, methods and frequencies. Lepr Rev, 1994; 65: 204-221.

23 Mafoyane NA, Lucas SB, Khawas IB. Primary neuritic leprosy in a black South Africa. Lepr Rev, 1992; 63: $277-281$.

${ }^{24}$ Barros U, Shetty VP, Antia NH. Demonstration of mycobacterial antigens in nerves in tuberculoid leprosy. Acta Neuropathol, 1987; 73: 387-392. 